\title{
The homogeneous and heterogeneous risk factors for the morbidity and prognosis of bone metastasis in patients with prostate cancer
}

This article was published in the following Dove Press journal:

Cancer Management and Research

\begin{abstract}
Xu Guo, ${ }^{1,2, *}$ Chao Zhang, ${ }^{1, *}$
Qi Guo, ',3,* Yao Xu,'

Guowei Feng, ${ }^{4}$ Lili Li,

Xiuxin Han,' Feng Lu,' Yulin

Ma,' Xin Wang, ${ }^{5}$ Guowen

Wang'

'Department of Bone and Soft

Tissue Tumors, Tianjin Medical

University Cancer Institute and

Hospital, National Clinical Research

Center for Cancer, Key Laboratory

of Cancer Prevention and Therapy,

Tianjin's Clinical Research Center for

Cancer, Tianjin, China; ${ }^{2}$ Department

of Orthopedics, Cangzhou Central

Hospital, Cangzhou, Hebei, China;

${ }^{3}$ Department of Orthopedics, General Hospital of North China Petroleum

Administration, Renqiu, Hebei, China;

${ }^{4}$ Department of Urology, Tianjin

Key Laboratory of Breast Cancer

Prevention and Therapy, Ministry of

Education, National Clinical Research

Center for Cancer, Tianjin Medical

University Cancer Institute and

Hospital, Tianjin, China; ${ }^{5}$ Department of Epidemiology and Biostatistics, First Affiliated Hospital, Army Medical University, Chongqing, China
\end{abstract}

*These authors contributed equally to this work

Correspondence: Xin Wang

Department of Epidemiology and

Biostatistics, First Affiliated Hospital,

Army Medical University, 30 Gaotanyan

Street Shapingba District, Chongqing

400038, China

Email wangxinmarine@126.com

Guowen Wang

Tianjin Medical University Cancer

Institute and Hospital, Huanhu Xi Road,

Tianjin 300060, China

Email wgwhrb@163.com
Purpose: Using the Surveillance, Epidemiology, and End Results database (SEER) to assess the incidence and risk factors of morbidity and prognosis for bone metastases in initial metastatic prostate cancer.

Patients and methods: The records of 249,331 prostate cancer patients in the SEER database, diagnosed between 2010 and 2014, were obtained were obtained to investigate the risk factors for developing bone metastasis, and the records of 9925 of them who registered before 2013 were retrieved (with at least 1 year follow up) to explore the prognostic factors for bone metastasis. Multivariate logistic and Cox regression were used to identify risk factors and prognostic factors for bone metastases, respectively.

Results: In total, 12,794 patients $(5.1 \%)$ were diagnosed with bone metastases at the initial diagnosis. Older age, unmarried status, lymph node metastasis, poor tumor differentiation grade (Gleason grade), metastases at lung, brain, and liver were all positively associated with risk for the morbidity and prognosis of bone metastasis in prostate cancer. Black race and higher $\mathrm{T}$ stage were positively associated with bone metastasis development; however, they were not associated with a prognosis of bone metastasis.

Conclusion: The incidence of bone metastasis in prostate cancer was approximately $5 \%$ with poor survival. The prostate cancer has homogeneous and heterogeneous risk factors for incidence and prognosis of bone metastasis, which may provide potential guidelines for the screening and preventive treatment for the bone metastasis of prostate cancer.

Keywords: bone metastases, initial prostate cancer, survival, risk factor

\section{Introduction}

Globally, prostate cancer is the second most common malignancy in males and the fifth leading cancer-related cause of death. ${ }^{1,2}$ In the US, prostate cancer is the most common malignancy in males, and takes up $19 \%$ of all newly-diagnosed male cancer cases. ${ }^{1}$ With the development of surgical technique, radiotherapy, and chemotherapy, biotherapy regimen, and supportive treatment, the survival of prostate cancer patients has increased. ${ }^{3-5}$ Accordingly, the higher survival rate increased the prevalence of distant metastasis. Bone metastases (BM), as one of the most common distant metastasis types, was reported to occur in at least $85 \%$ of patients who died from prostate cancer. ${ }^{5}$ BM was accepted to lead to significant morbidity, worsening patient quality-of-life. ${ }^{6}$

Usually, the three most common clinical symptoms of BM can be detected, including pain, pathologic bone fractures, and spinal cord compression. ${ }^{7}$ A large number of prostate cancer patients did not go to a doctor until they had the aforementioned symptoms. Furthermore, for asymptomatic patients, the Prostate Cancer National 
Comprehensive Cancer Network (NCCN) screening guidelines do not recommend performing routine assessment for BM. ${ }^{8}$ Hence, to build a reliable predictive system for screening performance; a study looking into the risk factors of BM in prostate cancer patients is warranted.

Currently, prostate specific antigen (PSA) has been clinically applied as the main predictor for BM. ${ }^{9}$ However, using PSA level as the inclusion criteria, the latest systematic review and meta-analysis suggested the lack of a robust definition for predicting high BM risk in prostate cancer patients. ${ }^{10}$ Meanwhile, a series of clinical studies suggested the incidence of BM in prostate patients with low PSA values $(<20 \mathrm{ng} /$ $\mathrm{mL}$ ) is from $12.6 \%$ to $36.1 \% .{ }^{11-13}$ A previous study reported, besides PSA, Gleason score can be another predictive factor in prostate cancer patients with BM. ${ }^{14}$ More BM risk factors are needed to uncover the clinical metastatic characteristics of prostate cancer, and to supplement the predictive system.

The purpose of the present study was to use the Surveillance, Epidemiology, and End Results (SEER) database to assess the incidence and the risk factors of BM in initial prostate cancer. Moreover, survival estimates and prognostic factors identification were conducted for patients who had developed $\mathrm{BM}$ at the time of prostate cancer diagnosis.

\section{Methods}

\section{Data source and cohort selection}

Data were obtained from the National Cancer Institute's SEER program between 2010 and 2014, as the BM status and other sites of distant metastases were collected by SEER from 2010, and the latest data update was on December 31, 2014. We extracted data for all cases initially diagnosed as malignant primary prostate cancer. The flow-chart of the subjects' selection is listed in Figure 1. A total of 249,331 patients who were diagnosed as having prostate cancer with or without BM between January 1, 2010 and December 31, 2014 were utilized to identify the risk factors of BM. Among them, 9,925 patients who were diagnosed between 2010 and 2013 (with at least 1 year follow up) were retrieved for analyzing the prognosis factors for bone metastasis in prostate cancer (Figure 1).

The SEER is a freely available database, and the data released by the SEER database do not require informed patient consent, because cancer is a reportable disease in every state of the USA. The present study complied with the 1964 Helsinki Declaration and its later amendments or comparable ethical standards, and the study was approved by the research ethics board of the Tianjin Medical University Cancer Institute and Hospital.

\section{Statistical analysis}

Multivariable logistic regression was used to determine the risk factors for developing $\mathrm{BM}$ at diagnosis. Variables included age ( $\leq 40,41-60,61-80$, and $\geq 81$ years), race [white, black, American Indian/Alaska Native (AI) and Asian or Pacific Islander (API)], marital status (married and unmarried), primary tumor ( $\mathrm{T}$ ) stage (T1, T2, T3, and T4), regional lymph node stage (N0 and N1), Gleason tumor grade (1= Gleason score $\leq 6 ; 2=$ Gleason score $3+4 ; 3=$ Gleason score $4+3$; 4= Gleason score 8; 5= Gleason score 9-10), and the presence or absence of lung metastases, liver metastases, or brain metastases. Survival duration was obtained using the Kaplan-Meier method; the differences between the curves were tested by Log-rank test. To identify factors associated with mortality, multivariable Cox proportional hazards regression was performed using the aforementioned factors.

All statistical analyses were performed using SPSS 23.0 (IBM Corporation, Armonk, NY, USA), and all charts of survival were prepared using MedCalc 15.2.2. Two-sided $P$-values less than 0.05 were considered statistically significant. SEER*Stat Software version 8.3.4 (Information Management Sercives, Inc. Calverton, MD, USA) (The Surveillance Research Program of the Division of Cancer Control and Population Sciences, National Cancer Institute) was used to extract data.

\section{Results \\ Incidence of bone metastases}

For the 249,331 eligible patients who were diagnosed with malignant primary prostate cancer between 2010 and 2014 in the study, the mean age was $66.08 \pm 9.22$ years, and 190,863 (76.6\%) were white. Of them, 12,794 (5.1\%) were diagnosed with $\mathrm{BM}$ at the initial diagnosis (Table 1).

\section{Risk factors for developing bone metastasis}

As shown in Table 1, age over 80 years, black race, unmarried, higher $\mathrm{T}$ stage, lymph node involvement, poor tumor differentiated grade (Gleason grade), and the presence of lung metastases, liver metastases, and brain metastases were associated with significantly greater odds of having BM at diagnosis.

\section{Survival and prognostic factors for BM}

The mean survival of the prostate cancer patients was $28.53 \pm 17.60$ months, while that of those patients with BM was only $20.44 \pm 14.57$ months. Survival estimates classified by age (Figure 2A), race (Figure 2B), marital 


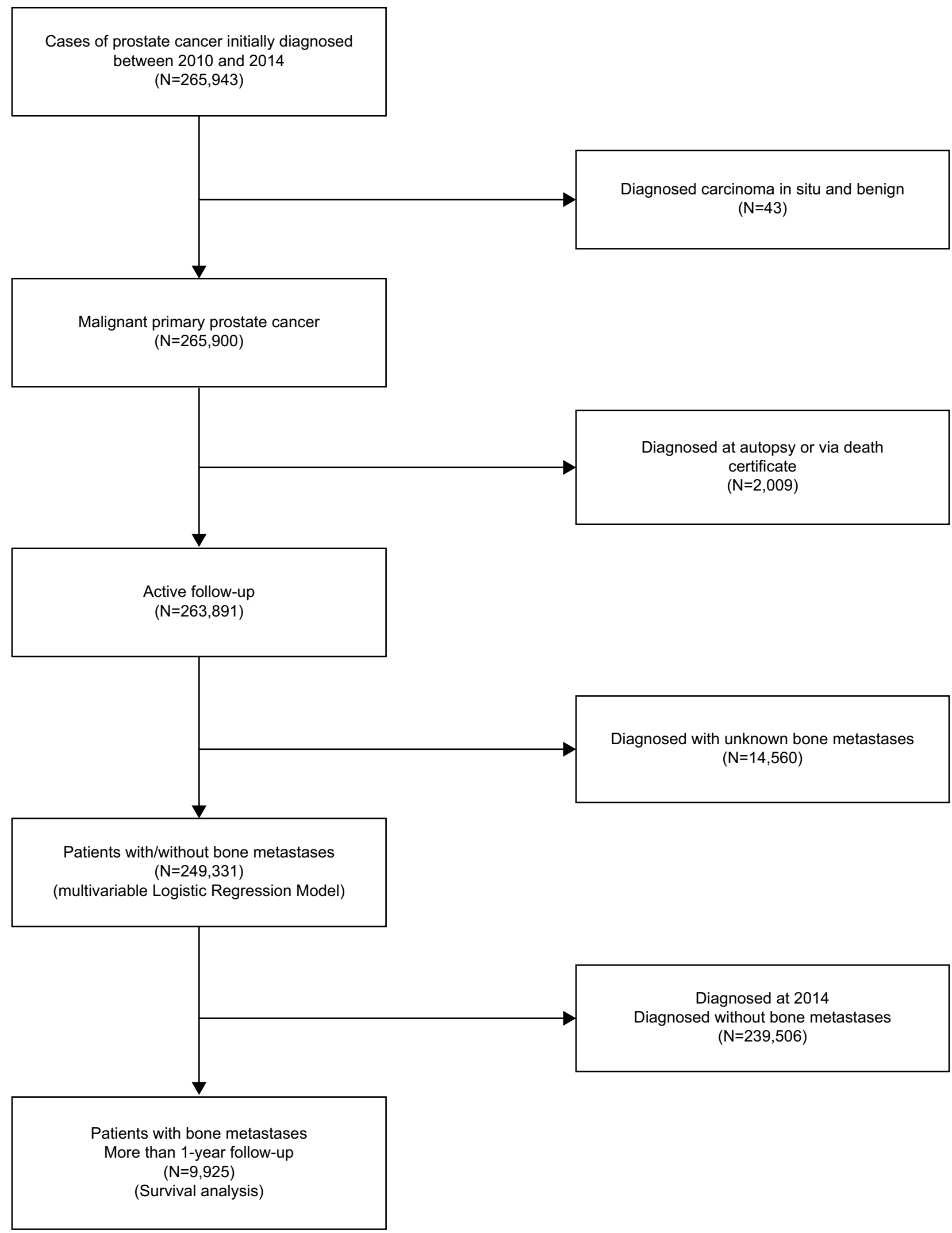

Figure I Flow chart of the subject's selection for analyzing the risk factors for the morbidity and prognosis of BM in prostate cancer patients. Abbreviations: BM, bone metastases. 
Table I Multivariable logistic regression for analyzing the demographic and related clinical characteristics for developing BM in patients diagnosed with initial primary prostate cancer (diagnosed 2010-2014)

\begin{tabular}{|c|c|c|c|c|c|}
\hline \multirow{2}{*}{$\begin{array}{l}\text { Subject } \\
\text { characteristics }\end{array}$} & \multicolumn{3}{|c|}{ No. of patients with PC (20 I0-20I4) } & \multirow[t]{2}{*}{ OR (95\%Cl) } & \multirow[t]{2}{*}{$P$ value } \\
\hline & $\begin{array}{l}\text { With bone } \\
\text { metastases }\end{array}$ & $\begin{array}{l}\text { Entire } \\
\text { cohort }\end{array}$ & $\begin{array}{l}\text { Incidence } \\
(\%)\end{array}$ & & \\
\hline Age, in years & & & & $1.45(1.37-1.53)$ & $<0.001$ \\
\hline$\leq 40$ & II & 273 & 4.02 & I (Reference) & 1.00 \\
\hline $4 I-60$ & 2,240 & 68,525 & 3.27 & $0.65(0.21-1.99)$ & 0.45 \\
\hline $6 I-80$ & 7,148 & 163,679 & 4.39 & $0.64(0.21-1.96)$ & 0.43 \\
\hline$\geq 81$ & 3,395 & 16,854 & 20.14 & $1.22(0.40-3.75)$ & 0.73 \\
\hline Race & & & & $1.06(1.04-1.08)$ & $<0.001$ \\
\hline White & 9,652 & 190,863 & 5.06 & I (Reference) & 1.00 \\
\hline Black & 2,270 & 38,370 & 5.92 & $1.19(1.10-1.29)$ & $<0.001$ \\
\hline Al & 91 & 978 & 9.30 & $0.97(0.85-1.11)$ & 0.63 \\
\hline API & 688 & $|I, 47|$ & 6.00 & $1.00(0.64-1.57)$ & 0.99 \\
\hline Unknown & 93 & 7,649 & 1.21 & NA & NA \\
\hline \multicolumn{6}{|l|}{ Marital status } \\
\hline Unmarried & 4,985 & 55,193 & 9.03 & I (Reference) & 1.00 \\
\hline Married & 6,970 & $|57,77|$ & 4.42 & $0.64(0.60-0.68)$ & $<0.001$ \\
\hline Unknown & 839 & 36,367 & 2.31 & NA & NA \\
\hline T stage & & & & $0.91(0.88-0.95)$ & $<0.001$ \\
\hline TI & 2,753 & 99,988 & 2.75 & I (Reference) & 1.00 \\
\hline $\mathrm{T} 2$ & 3,502 & 112,984 & 3.10 & $0.83(0.77-0.89)$ & $<0.001$ \\
\hline T3 & 1,106 & 25,640 & 4.31 & $0.39(0.36-0.43)$ & $<0.001$ \\
\hline $\mathrm{T} 4$ & $\mathrm{I}, 453$ & 2,874 & 50.56 & $2.64(2.31-3.01)$ & $<0.001$ \\
\hline Unknown & 3,980 & 7,845 & 50.73 & NA & NA \\
\hline \multicolumn{6}{|l|}{ N stage } \\
\hline No & 6,781 & 232,945 & 2.91 & I (Reference) & 1.00 \\
\hline $\mathrm{NI}$ & 2,932 & 7,922 & 37.01 & $4.80(4.43-5.20)$ & $<0.001$ \\
\hline Unknown & 3,081 & 8,464 & 36.40 & NA & NA \\
\hline Gleason grade & & & & $2.88(2.8 \mathrm{I}-2.96)$ & $<0.001$ \\
\hline 1 & 232 & 103,197 & 0.22 & I (Reference) & 1.00 \\
\hline 2 & 456 & 61,745 & 0.74 & $3.06(2.54-3.70)$ & $<0.001$ \\
\hline 3 & 675 & 28,146 & 2.40 & $10.26(8.60-12.25)$ & $<0.001$ \\
\hline 4 & 1,905 & 23,513 & 8.10 & $29.40(24.95-34.65)$ & $<0.001$ \\
\hline 5 & 4,354 & 20,213 & 21.54 & $75.65(64.42-88.83)$ & $<0.001$ \\
\hline Unknown & 5,172 & 12,517 & 41.32 & NA & NA \\
\hline \multicolumn{6}{|l|}{ Lung Met } \\
\hline None & 11,222 & 247,403 & 4.54 & I (Reference) & 1.00 \\
\hline Yes & 902 & 1,125 & 80.18 & $22.39(16.86-29.72)$ & $<0.001$ \\
\hline Unknown & 670 & 803 & 83.43 & $\mathrm{NA}$ & NA \\
\hline \multicolumn{6}{|l|}{ Liver Met } \\
\hline None & $\mathrm{II}, 757$ & 248,017 & 4.74 & I (Reference) & 1.00 \\
\hline Yes & 483 & 641 & 75.35 & $18.79(12.58-28.06)$ & $<0.001$ \\
\hline Unknown & 554 & 673 & 82.32 & NA & NA \\
\hline \multicolumn{6}{|l|}{ Brain Met } \\
\hline None & 11,980 & 248,365 & 4.82 & I (Reference) & 1.00 \\
\hline Yes & 153 & 179 & 85.47 & $28.64(11.92-68.77)$ & $<0.001$ \\
\hline Unknown & 661 & 787 & 83.99 & NA & NA \\
\hline
\end{tabular}

Note: All factors with unknown data removed from multivariable logistic regression model.

Abbreviations: BM, bone metastases; PC, prostate cancer; Al, American Indian/Alaska Native; API, Asian or Pacific Islander; Met, metastases; NA, not available.

status (Figure 2C), T stage (Figure 2D), N stage (Figure $2 \mathrm{E}$ ), tumor grade (Figure $2 \mathrm{~F}$ ), the presence of lung metastases (Figure 2G), liver metastases (Figure $2 \mathrm{H}$ ) or brain metastases (Figure 2I) are graphically displayed. Among patients with initial bone metastasis, the median survival of those who combined with liver metastases was the shortest (Median survival=10 months, 95\% CI=8.44-11.56 months).

The prognostic factors for BM are shown in Table 2. A multivariate Cox regression model showed that patients of older age, unmarried, with lymph node involvement, poor tumor differentiated grade, and the presence of lung metas- 
A

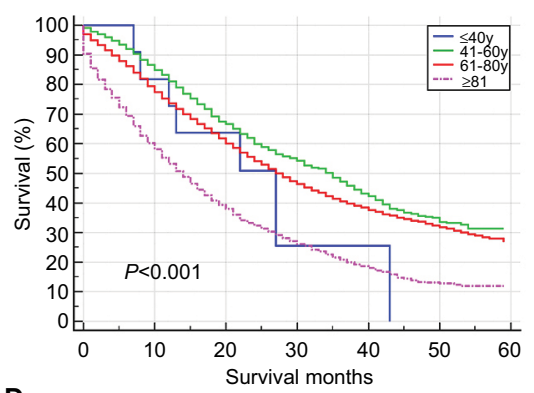

D

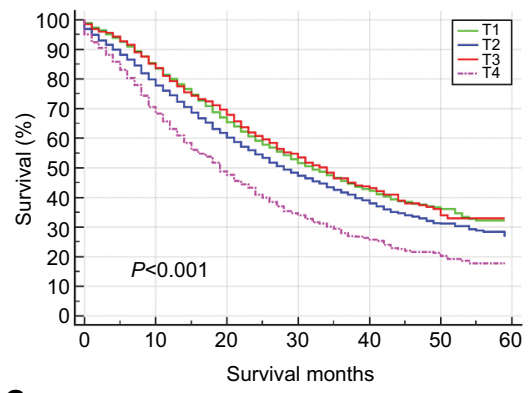

G

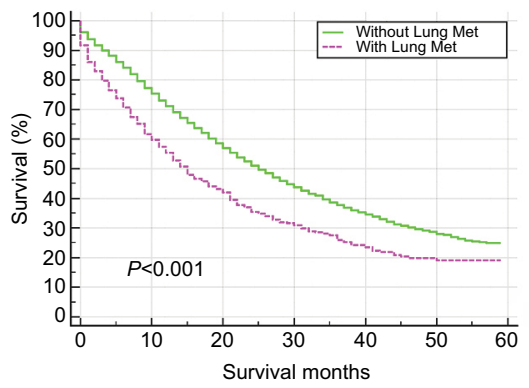

B

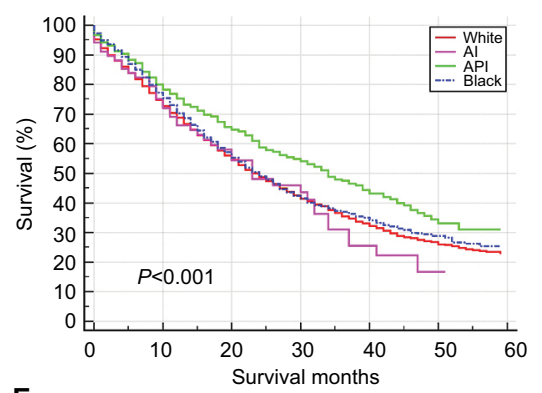

E

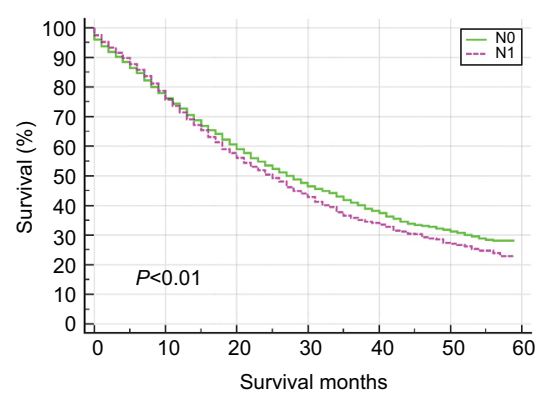

H

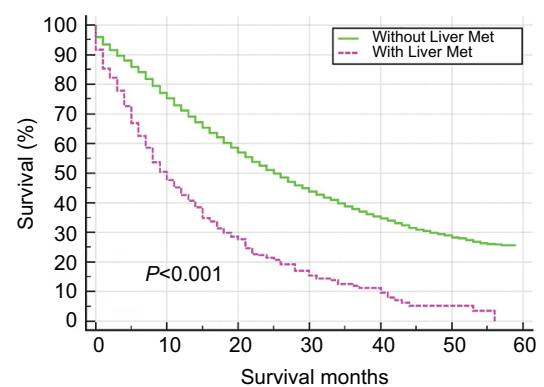

C

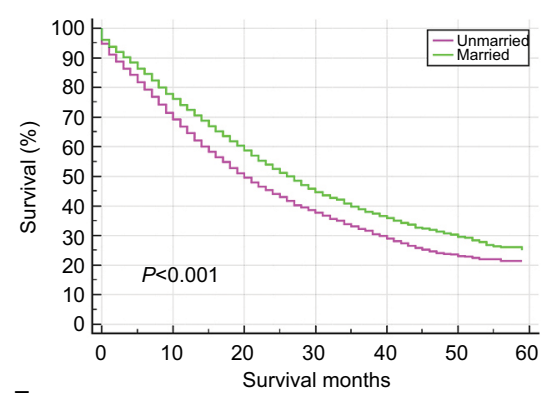

F

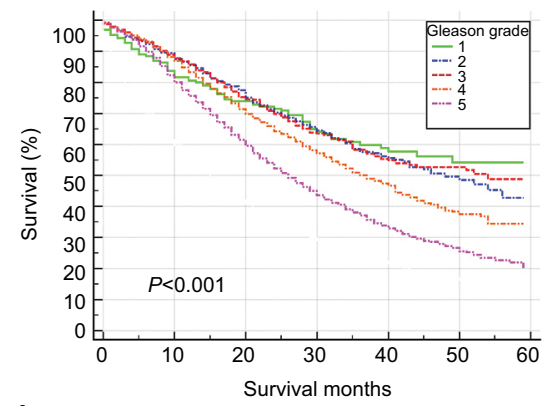

I

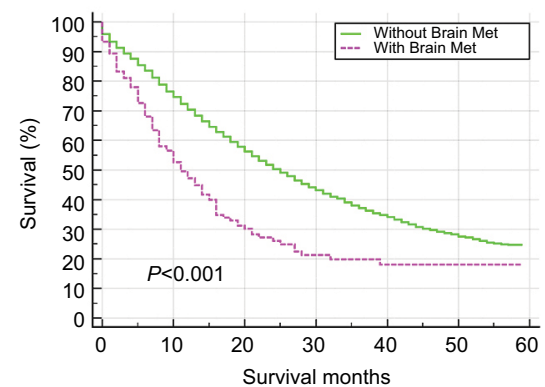

Figure 2 Kaplan-Meier analysis of overall survival among prostate cancer patients who were diagnosed with BM, when stratified by age $(\mathbf{A})$, race $(\mathbf{B})$, marital status $(\mathbf{C})$, $\mathbf{T}$ stage (D), N stage (E), Gleason grade (F), and the presence of lung metastases (G), liver metastases (H), and brain metastases (I).

Abbreviations: BM, bone metastases; Lung Met, lung metastases; Liver Met, liver metastases; Brain Met, brain metastases; Al, American Indian/Alaska Native; API, Asian or Pacific Islander; $y$, years.

tases, liver metastases, and brain metastases were correlated with higher risk of mortality. Race and $\mathrm{T}$ stage were not significantly associated with mortality.

In this study, the homogeneous risk factors for the morbidity and prognosis of BM in patients with prostate cancer were older, unmarried status, lymph node involvement, poor tumor differentiated, and the presence of lung, liver, or brain metastases. Patients with black race and higher T stage were prone to be associated with BM development; however, they were not associated with overall survival of BM.

\section{Discussion}

Based on a large population analysis, the present study firstly determined the incidence of BM at the initial diagnosis of prostate cancer patients. We found that $5.1 \%$ of prostate cancer patients were initially diagnosed with BM. Although the present study was conducted based on a large population, it may underestimate BM incidence in initial diagnosed prostate cancer patients for being unable to capture the asymptomatic cases. The BM cumulative incidence was differently reported from $0.8 \%$ to $53.6 \% .^{11,15-18}$ The diversity of BM cumulative incidence could be due to various causes: First, most of the prostate patients chose to go to a doctor at an advanced stage in developing countries; Secondly, a high incidence of BM can also be observed in developed countries in the $1990 \mathrm{~s} .{ }^{17,18}$ Thus, a metastatic screening for prostate cancer patients should be designed based on local economic development and local epidemiologic characteristics of prostate cancer.

A series of risk factors of initial BM in prostate cancer patients were found, including elderly patient ( $\geq 81$ years), black race, unmarried, higher $\mathrm{T}$ stage, $\mathrm{N}$ stage (N1), lung metastases, brain metastases, and poor tumor differentiated grade. Thus, physicians should focus on their prostate cancer patients with these risk factors. At the same time, a skeletal scanning can be considered for the patients with high 
Table 2 Multivariable Cox regression for analyzing the mortality among primary prostate cancer patients with BM (diagnosed 20I02013)

\begin{tabular}{|c|c|c|c|c|c|}
\hline \multirow{2}{*}{$\begin{array}{l}\text { Subject } \\
\text { characteristics }\end{array}$} & \multicolumn{2}{|c|}{ No. of PC patients with BM } & \multirow{2}{*}{$\begin{array}{l}\text { Survival, } \\
\text { Median (IQR), mo }\end{array}$} & \multirow{2}{*}{$\begin{array}{l}\text { Cox HR } \\
(95 \% \mathrm{Cl})\end{array}$} & \multirow[t]{2}{*}{$P$ value } \\
\hline & Overall & Deceased (rate, \%) & & & \\
\hline Age, in years & & & & $1.43(1.33-1.53)$ & $<0.001$ \\
\hline$\leq 40$ & II & $7(63.64)$ & $27(|2.8|-4 \mid .19)$ & I (Reference) & 1.00 \\
\hline $4 I-60$ & $\mathrm{I}, 748$ & $839(48.00)$ & $35(32.65-37.35)$ & $0.58(0.14-2.32)$ & 0.44 \\
\hline $61-80$ & 5,521 & $2,958(53.58)$ & $27(25.87-28.14)$ & $0.70(0.18-2.83)$ & 0.62 \\
\hline$\geq 81$ & 2,645 & $1,936(73.19)$ & $14(13.12-14.88)$ & $\mathrm{I} .17(0.29-4.7 \mathrm{I})$ & 0.82 \\
\hline Race & & & & $1.02(0.99-1.05)$ & 0.13 \\
\hline White & 7,464 & $4,388(58.79)$ & $23(22.14-23.86)$ & I (Reference) & 1.00 \\
\hline Black & $\mathrm{I}, 790$ & $\mathrm{I}, 037(57.93)$ & $24(22.37-25.63)$ & $1.13(1.01-1.26)$ & 0.03 \\
\hline $\mathrm{Al}$ & 68 & $44(64.70)$ & $23(12.42-33.58)$ & $0.73(0.58-0.91)$ & 0.01 \\
\hline API & 534 & $250(46.82)$ & $34(28.99-39.02)$ & $0.77(0.40-1.48)$ & 0.43 \\
\hline Unknown & 69 & $21(30.43)$ & NA & NA & NA \\
\hline \multicolumn{6}{|l|}{ Marital status } \\
\hline Unmarried & 3,859 & $2,403(62.27)$ & $20(|8.94-2| .06)$ & I (Reference) & 1.00 \\
\hline Married & 5,433 & $3,000(55.22)$ & $27(25.92-28.08)$ & $0.81(0.74-0.89)$ & $<0.001$ \\
\hline Unknown & 633 & 337 (53.24) & NA & NA & NA \\
\hline T Stage & & & & $1.04(0.99-1.08)$ & 0.12 \\
\hline TI & 2,155 & $\mathrm{I}, 042(48.35)$ & $32(29.80-34.21)$ & I (Reference) & 1.00 \\
\hline $\mathrm{T} 2$ & 2,769 & I,492 (53.88) & $28(26.18-29.82)$ & $0.94(0.85-1.03)$ & 0.19 \\
\hline T3 & 837 & 400 (47.79) & $34(30.48-37.52)$ & $0.85(0.74-0.98)$ & 0.03 \\
\hline $\mathrm{T} 4$ & 1,105 & $726(65.70)$ & $19(17.20-20.81)$ & $1.23(1.07-1.4 I)$ & 0.003 \\
\hline Unknown & 3,059 & $2,080(68.00)$ & NA & NA & NA \\
\hline \multicolumn{6}{|l|}{ N Stage } \\
\hline No & 5,272 & $2,829(53.66)$ & $28(26.67-29.33)$ & I (Reference) & 1.00 \\
\hline NI & 2,156 & I,227 (56.9I) & $25(23.38-26.62)$ & $1.11(1.01-1.23)$ & 0.036 \\
\hline Unknown & 2,497 & I,684 (67.44) & NA & NA & NA \\
\hline Gleason grade & & & & $1.26(1.20-1.32)$ & $<0.001$ \\
\hline 1 & 193 & $72(37.30)$ & NA & I (Reference) & 1.00 \\
\hline 2 & 381 & 155 (40.68) & $48(40.20-55.80)$ & I.I2 (0.79-I.57) & 0.52 \\
\hline 3 & 536 & $202(37.69)$ & $54(N R)$ & $1.22(0.88-1.69)$ & 0.23 \\
\hline 4 & $\mathrm{I}, 488$ & $672(45.16)$ & $37(34.33-39.68)$ & $1.32(0.98-1.78)$ & 0.07 \\
\hline 5 & 3,351 & I,87I (55.83) & $26(24.75-27.25)$ & $2.03(1.52-2.72)$ & $<0.001$ \\
\hline Unknown & 3,976 & $2,798(70.37)$ & NA & NA & NA \\
\hline \multicolumn{6}{|l|}{ Lung Met } \\
\hline None & 8,694 & $4,9 \mid 2(56.50)$ & $25(24.15-25.85)$ & I (Reference) & 1.00 \\
\hline Yes & 687 & $47 \mid(68.56)$ & $15(13.00-17.00)$ & I.43 (I.20-I.7I) & $<0.001$ \\
\hline Unknown & 544 & 357 (64.44) & NA & NA & NA \\
\hline \multicolumn{6}{|l|}{ Liver Met } \\
\hline None & 9,084 & $5,118(56.34)$ & $25(24.17-25.83)$ & I (Reference) & 1.00 \\
\hline Yes & 388 & 321 (82.73) & $10(8.44-11.56)$ & 2.5 I (2.05-3.09) & $<0.001$ \\
\hline Unknown & 453 & $301(66.45)$ & NA & NA & NA \\
\hline \multicolumn{6}{|l|}{ Brain Met } \\
\hline None & 9,257 & $5,280(57.04)$ & $25(24.19-25.81)$ & I (Reference) & 1.00 \\
\hline Yes & 133 & $99(74.44)$ & $11(8.05-13.95)$ & $1.80(1.16-2.78)$ & 0.01 \\
\hline Unknown & 535 & 361 (67.48) & NA & NA & NA \\
\hline
\end{tabular}

Note: All factors with Unknown Data removed from Cox and Kaplan-Meier model.

Abbreviations: PC, prostate cancer; BM, bone metastases; Al, American Indian/Alaska Native; API, Asian or Pacific Islander; Met, metastases; NA, not available; NR, not reached.

metastasis risk. Meanwhile, in future research, the factors we analyzed can be involved in the predictive system for initial $\mathrm{BM}$ in prostate cancer patients.

A series of prognostic factors of initial BM in prostate cancer patients, which were correlated with higher mortality risk, were found, including young ( $\leq 40$ years) and elderly patient
( $\geq 81$ years), unmarried, N stage (N1), poor tumor grade, lung metastases, and brain metastases. The result suggested Gleason grading system's affirmative ability on prevention prognosis of advanced cancer with BM. Based on the aforementioned prognostic factors, physicians can make a preliminary estimation for the prostate patients with initial BM. 


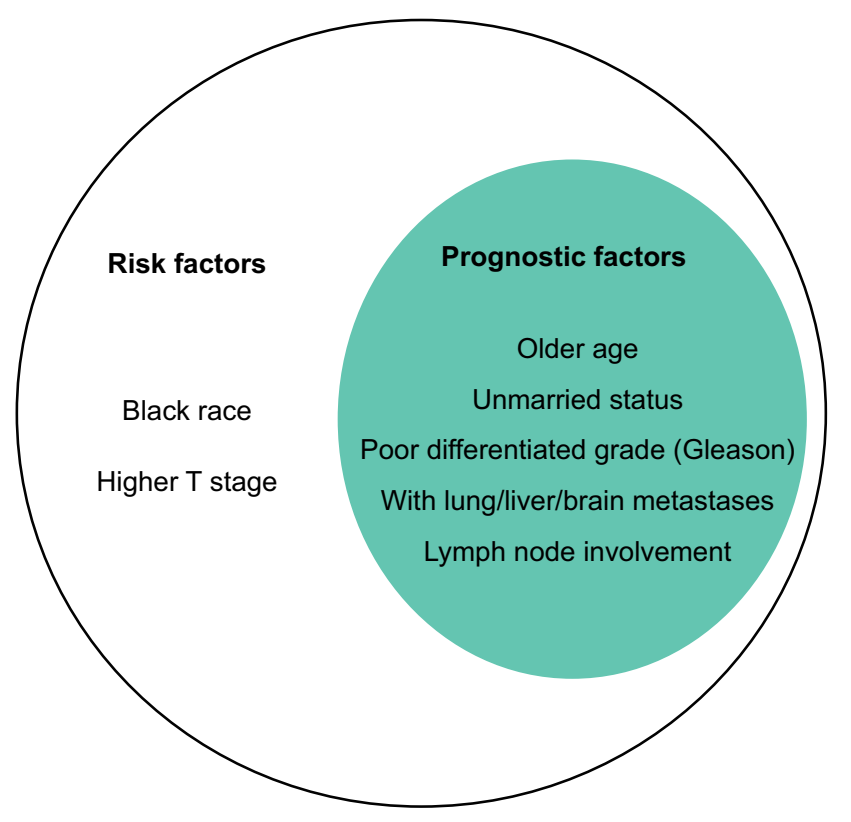

Figure 3 The homogeneous and heterogeneous risk factors and prognosis factor of BM in patients with prostate cancer. All the factors included in the larger circle represent the risk factors for developing BM, and the ones in smaller circle exhibit the factors, which were positively associated with overall death risk for prostate cancer patients with BM.

Abbreviation: BM, bone metastases.

Among the cohort of the present study, compared with black race, white patients had significantly lower risk for developing BM at diagnosis. This may suggest that prostate cancers in white patients are likely being diagnosed at an early stage. Meanwhile, black patients with BM showed worse median survival (Table 2). The latest study looking into brain metastases in newly diagnosed breast cancer also suggested a poor median survival in black patients. ${ }^{19}$ Further studies looking into the potential explanations for black patients' poor survival in metastatic tumor is needed.

Inevitably, the present study has several limitations. First, in the present study, only the presence/absence of BM based on the initial diagnosis was analyzed. The patients who developed BM later during their disease course could not be analyzed, as they may not be recorded in the SEER database. Second, the actual rate of $\mathrm{BM}$ in patients with prostate cancer might be underestimated. BM cannot be captured in asymptomatic prostate cancer patients. Third, the SEER database has a lack of intact baseline information. Performance status, smoking and alcohol consumption, family history, blood type, and body mass index were not provided in the SEER database. Last, but not least, the detailed diagnosis method for BM was not available.

\section{Conclusion}

Despite the aforementioned limitations, based on the SEER database, the present study provided the incidence risk factors and prognostic factors of BM in patients with newly diagnosed initial prostate cancer. A series of risk factors for $\mathrm{BM}$ in prostate cancer patients were identified, which can be potentially used for clinical prediction. Survival analysis was also conducted, and a series of prognostic factors of initial $\mathrm{BM}$ in prostate cancer patients were found, which can be potentially used for making an individualized treatment plan.

\section{Acknowledgments}

The present study was sponsored by the Natural Science Foundation of China $(81602363,81702161)$, the Natural Science Foundation of Tianjin Science and Technology Committee China (17JCQNJC11000), the Natural Science Foundation of Tianjin Medical University (2016KYZQ10), the China Postdoctoral Science Foundation Grant (2017M621091), and the Doctor Start-up Grant of Tianjin Medical University Cancer Institute and Hospital (B1612, B1711).

\section{Author contributions}

$\mathrm{XG}, \mathrm{CZ}$, and $\mathrm{XW}$ designed the study. YX and GF collected the data. $\mathrm{XG}$ and $\mathrm{XW}$ analyzed the data. $\mathrm{XG}, \mathrm{CZ}$, and QG organized the manuscript. LL, XH, YM, FL, and GW reviewed the papers and revised the manuscript. All the authors (XG, CZ, QG, YX, GF, LL, XH, FL, YM, XW, GW) have read and approved the final manuscript. All authors contributed toward data analysis, drafting, and revising of the paper and agree to be accountable for all aspects of the work.

\section{Disclosure}

The authors report no conflicts of interest in this work.

\section{References}

1. Torre LA, Bray F, Siegel RL, Ferlay J, Lortet-Tieulent J, Jemal A. Global cancer statistics, 2012. CA Cancer J Clin. 2015;65(2):87-108.

2. Ryerson AB, Eheman CR, Altekruse SF, et al. Annual Report to the Nation on the Status of Cancer, 1975-2012, featuring the increasing incidence of liver cancer. Cancer. 2016;122(9):1312-1337.

3. Xiao WJ, Zhu Y, Zhu Y, Dai B, Ye DW. Evaluation of clinical staging of the American Joint Committee on Cancer (eighth edition) for prostate cancer. World J Urol. 2018;36(5):769-774.

4. Berg KD, Thomsen FB, Mikkelsen MK, et al. Improved survival for patients with de novo metastatic prostate cancer in the last 20 years. Eur J Cancer. 2017;72:20-27.

5. Steele CB, Li J, Huang B, Weir HK. Prostate cancer survival in the United States by race and stage (2001-2009): findings from the CONCORD-2 study. Cancer. 2017;123(Suppl 24):5160-5177.

6. Mangano AM, Pacilio M, Ialongo P, Semprebene A, Ventroni G, Mango L. Dosimetry-based consideration on remission and relapse after therapy with 223Ra-dichloride in castration-resistant prostate cancer (CRPC) with bone metastases. A case report. Diagnostics (Basel). 2018;8(1):pii. E18.

7. Saad F, Gleason DM, Murray R, et al. A randomized, placebo-controlled trial of zoledronic acid in patients with hormone-refractory metastatic prostate carcinoma. J Natl Cancer Inst. 2002;94(19):1458-1468. 
8. Network NCC. NCCN Clinical Practice Guidelines in Oncology. Prostate Cancer. Version 2. 2016. Available from: https: //www.nccn. org/professionals/physician_gls/pdf /prostate.pdf. Accessed March 15 th, 2018.

9. Fonager RF, Zacho HD, Langkilde NC, et al. Diagnostic test accuracy study of 18F-sodium fluoride PET/CT, 99mTc-labelled diphosphonate SPECT/CT, and planar bone scintigraphy for diagnosis of bone metastases in newly diagnosed, high-risk prostate cancer. $\mathrm{Am} \mathrm{J} \mathrm{Nucl} \mathrm{Med} \mathrm{Mol}$ Imaging. 2017;7(5):218-227.

10. Hayes AR, Brungs D, Pavlakis N. Osteoclast inhibitors to prevent bone metastases in men with high-risk, non-metastatic prostate cancer: a systematic review and meta-analysis. PLoS One. 2018;13(1):e0191455.

11. Sanjaya IP, Mochtar CA, Umbas R. Correlation between low Gleason score and prostate specific antigen levels with incidence of bone metastases in prostate cancer patients: when to omit bone scans? Asian Pac J Cancer Prev. 2013;14(9):4973-4976.

12. Ito K, Kubota Y, Suzuki K, et al. Correlation of prostate-specific antigen before prostate cancer detection and clinicopathologic features: evaluation of mass screening populations. Urology. 2000;55(5):705-709.

13. Zaman MU, Fatima N, Sajjad Z. Metastasis on bone scan with low prostate specific antigen $(\leq 20 \mathrm{ng} / \mathrm{ml})$ and Gleason's score $(<8)$ in newly diagnosed Pakistani males with prostate cancer: should we follow Western guidelines? Asian Pac J Cancer Prev. 2011;12(6):1529-1532.
14. Rodríguez-Antolín A, Gómez-Veiga F, Alvarez-Osorio JK, et al. Factors that predict the development of bone metastases due to prostate cancer: recommendations for follow-up and therapeutic options. Actas Urol Esp. 2014;38(4):263-269.

15. Briganti A, Passoni N, Ferrari M, et al. When to perform bone scan in patients with newly diagnosed prostate cancer: external validation of the currently available guidelines and proposal of a novel risk stratification tool. Eur Urol. 2010;57(4):551-558.

16. Akaza H, Carroll P, Cooperberg MR, Hinotsu S. Fifth Joint Meeting of J-CaP and CaPSURE: advancing the global understanding of prostate cancer and its management. Jpn J Clin Oncol. 2012;42(3):226-236.

17. Rudoni M, Antonini G, Favro M, et al. The clinical value of prostatespecific antigen and bone scintigraphy in the staging of patients with newly diagnosed, pathologically proven prostate cancer. Eur J Nucl Med. 1995;22(3):207-211.

18. Haukaas S, Roervik J, Halvorsen OJ, Foelling M. When is bone scintigraphy necessary in the assessment of newly diagnosed, untreated prostate cancer? Br J Urol. 1997;79(5):770-776.

19. Martin AM, Cagney DN, Catalano P, et al. Brain metastases in newly diagnosed breast cancer: a population-based study. JAMA Oncol. 2017;3(8):1069-1077.
Cancer Management and Research

\section{Publish your work in this journal}

Cancer Management and Research is an international, peer-reviewed open access journal focusing on cancer research and the optimal use of preventative and integrated treatment interventions to achieve improved outcomes, enhanced survival and quality of life for the cancer patient. The manuscript management system is completely online and includes
Dovepress

a very quick and fair peer-review system, which is all easy to use. Visit http://www.dovepress.com/testimonials.php to read real quotes from published authors. 